\title{
Estratégia saúde da família: iniciativa pública destinada a populações vulneráveis para garantia do direto à saúde - uma revisão crítica da literatura
}

Family Health strategy: a public initiative aimed at materializing the right to health among vulnerable populations - a critical bibliographic review

Estrategia de salud de la familia: uns iniciativa pública dirigida a garantizar el derecho a la salud de las poblaciones vulnerables - una revisión crítica de la literatura

Samira Janis Eugenio ${ }^{1}$

Carla Aparecida Arena Ventura ${ }^{2}$

RESUMO: A Estratégia Saúde da Família (ESF) foi criada com o intuito de reorganizar o conceito de Atenção Básica no país com base princípio fundamental da equidade, integralidade e universalidade. Objetivo - identificar melhorias na qualidade de vida da população após a implantação da Estratégia Saúde da Família como tática para garantir o direito à saúde. Métodos - Revisão crítica da literatura nas bases de dados PubMed, LILACS, Web of Knowledge e CINAHL. Foram selecionados 12 estudos realizados no Brasil, no período de 2006 a 2011. Resultados - Nos lugares em que ocorreu a implantação do PSF houve uma sensível melhora na qualidade de vida dos indivíduos assistidos, suas famílias e comunidades. Os dados indicam a efetividade das ações de promoção à saúde implementadas por toda a equipe, em seus vários ramos de atuação, demonstrando que a ESF busca assegurar o efetivo cumprimento do direito à saúde voltando-se para o indivíduo de forma integral, assistindo-o em seus diversos níveis de complexidade e em seu próprio contexto social familiar e cultural. Conclusão - A ESF é uma estratégia nova e ainda passa por grandes dificuldades, entretanto é grande a sua potencialidade como agente de transformação de realidade e sustentação dos direitos dos indivíduos e populações, dentre eles o direito à saúde.

Palavras-chave: Saúde da Família. Pobreza. Direito à Saúde.

ABSTRACT: The Family Health Strategy (FHS) was created in order to reorganize the concept of primary care in the country based on its fundamental principle of fairness, completeness and universality. Objective - Assuming the Family Health Strategy was a strategy to ensure the right to health, this study seeks to identify improvements in the quality of life among vulnerable populations after its implementation. Methods - The chosen method consists of a literature's critical review. 12 studies conducted in Brazil during the period 20062011 were identified at the PubMed, Lilacs, Web of Knowledge and CINHAL databases. Results - A marked improvement in the quality and conditions of life of individuals assisted, their families and communities was identified in the sites where the FHS was implemented. The data points to the effectiveness of health promotion activities implemented by health

\footnotetext{
1 Universidade de São Paulo (USP). Escola de Enfermagem de Ribeirão Preto. E-mail: salendance12@hotmail.com 2 Escola de Enfermagem de Ribeirão Preto. Universidade de São Paulo. Ribeirão Preto, São Paulo. E-mail: caaventu@eerp.usp.br
} 
professionals in all areas of activity. It suggests that the FHS tries to ensure the effective fulfillment of the right to health by understanding individuals holistically, supporting them at their various levels of complexity and in their own family, social and cultural contexts. Conclusion - The FHS is a new strategy and is still experiencing considerable challenges. Notwithstanding the difficulties, of the strategy is promising as agent of transformation of reality and as a supporting tool to the rights of individuals, including the right to health.

Keywords: Family Health. Poverty. Right to Health.

RESUMEN: La Estrategia de Salud de la Familia (ESF) fue creada para reorganizar el concepto de atención primaria en Brasil y materializar los principios fundamentales de la equidad, la integridad y la universalidad. Objetivo - Considerando la Estrategia de Salud de la Familia como una táctica para tratar de asegurar el derecho a la salud, este estudio busca identificar mejoras en la calidad de vida de las poblaciones vulnerables después de su implementación. . Métodos - Por lo tanto, se decidió realizar una revisión crítica de la literatura. Las revisiones se realizaron en PubMed, Lilacs, Web of Knowledge y CINHAL y se seleccionaron 12 estudios realizados en Brasil, en el período 2006-2011. Resultados De acuerdo con el análisis de los resultados en los que hubo despliegue de la ESF hubo una notable mejoría en la calidad y condiciones de vida de las personas atendidas, sus familias y comunidades. Los datos indican la eficacia de las actividades de promoción de la salud implementadas por todo el personal en sus diversas áreas de actividad. Demostrando que la ESF trata de asegurar la duración efectiva del derecho a la salud, dirigiéndose al individuo de manera integral, holística, atendiéndolos en diversos niveles de complejidad y en su propio contexto social y cultural familiar. Conclusión - Por lo tanto, al igual que el SUS FHS es una nueva estrategia y sigue experimentando grandes dificultades, por muy grande que sea su potencial en la categoría de agente de transformación de la realidad y apoyar los derechos de las personas, incluido el derecho a la salud.

Palabras-Ilave: Salud de la Familia; Pobreza. Derecho a la Salud.

\section{Introdução}

Tradicionalmente, o conceito de saúde esteve ligado à religião, como um presente por bons comportamentos. Já os acidentes e adoecimentos eram considerados punições. (1) A saúde foi caracterizada como direito social inerente ao homem com a consolidação do movimento de proteção internacional dos direitos humanos, no contexto do pós-Segunda Guerra Mundial, quando se reafirmaram os direitos civis e políticos e os direitos econômicos, sociais e culturais. (2), (3),(4)

Várias conferencias mundiais foram realizadas como a de Alma Ata e Ottawa, que enfatizaram a relevância da equidade no campo da saúde e estabeleceram metas a serem cumpridas pelos países. (5), (6) No Brasil, até meados da década de 1980, o direito à saúde excluía boa parte da população e seu foco era voltado para o modelo biomédico. Com a 
queda da ditadura, a reforma política e a promulgação da nova Constituição em 1988, idealizou-se o Sistema Único de Saúde (SUS) e a extensão do direito à saúde à toda a população, embasada pela seção II desta nova constituição, a qual se refere à saúde e declara no art. 196 que "a saúde é direito de todos e dever do Estado". (7), (8)

Apesar de garantido em lei, o direito à saúde no país enfrenta uma série de entraves para sua consolidação, uma vez que as desigualdades socioeconômicas geram uma verdadeira exclusão social em saúde para parcelas da população, tornando-as mais vulneráveis. Estas desigualdades podem ser definidas como a diferença de acesso a recursos, deixando essa população em desvantagem e influenciando aspectos sociais e de saúde. (9), (10)

Para a correção dessas disparidades, algumas políticas foram surgindo, como estratégias das ações de promoção de saúde nos três níveis de gestão do Sistema Único de Saúde (SUS) para garantir a integralidade do cuidado (11). Dentre elas destaca-se a Estratégia Saúde da Família (ESF), que busca assegurar o efetivo cumprimento do direito à saúde, voltando-se para o indivíduo de forma integral, assistindo-o em seus diversos níveis de complexidade e em seu próprio contexto social, familiar e cultural (12).

A ESF coloca em prática a humanização da saúde por meio do vínculo criado entre os profissionais e os usuários trazendo uma nova perspectiva sobre o processo saúde-doença e dando abertura para que ocorra transformação social. O vínculo possibilita ao profissional ter a visão mais aguçada em relação aos usuários, suas carências e riscos relacionados a sua saúde. A ESF é apta a fazer parcerias e discutir com diferentes setores da saúde para a tomada de decisão mais assertiva (13).

O conhecimento sobre a saúde, seus direitos e deveres é estimulado na ESF e a população passa a entender seu direito a saúde como manifestação de qualidade de vida e há um estimulo à organização em comunidade e controle social por meio de conselhos de saúde. O Brasil conta com 32.970 ESFs. Equipes formadas por médicos, enfermeiros, técnicos ou auxiliares de enfermagem e até doze agentes comunitários atuam nas unidades básicas de saúde e junto às comunidades. Esses profissionais são responsáveis por famílias localizadas em uma área delimitada, atuando com ações de promoção da saúde, prevenção, recuperação, reabilitação da saúde (14). Considerando a evolução do direito à saúde no Brasil e sua relação com a Estratégia de Saúde da Família como meio para a promoção 
deste direito, o presente estudo apresentou como objetivo buscar evidências disponíveis na produção científica sobre a atuação da Estratégia Saúde da Família na garantia do direito à saúde da população.

\section{Metodologia}

Para o alcance do objetivo proposto, optou-se por realizar uma revisão integrativa da literatura, que permite a incorporação de evidências disponíveis na produção científica. É realizada de forma organizada, com o intuito de aprofundar conhecimentos em determinada temática. Para a execução desta revisão foram percorridas seis etapas descritas a seguir: identificação do tema e elaboração da questão norteadora, estabelecimento de critérios de inclusão e exclusão e seleção da amostragem, categorização dos estudos, avaliação dos estudos incluídos na revisão, discussão dos resultados e síntese do conhecimento (12) (16). Para guiar esta revisão, formulou-se a seguinte questão norteadora: Como a estratégia de saúde da família atua na garantia do direito à saúde de populações vulneráveis?

Para a busca dos artigos foram utilizadas as bases de dados PubMed, LILACS, Web of Knowledge e CINAHL. Os descritores empregados em inglês foram: "family health" AND (poverty OR "vulnerable population" OR "marginalized population"); Family Health" AND ("Poverty" OR "Vulnerable Populations"). Os descritores usados em português foram: Saúde da Família com as variações de palavras-chave: Aumento; Carentes; Diminuição; Taxa; Avaliação. E com o Descritor: Programa Saúde da Família foi usada as variações de palavras-chave: Contribuição; Desempenho; Impacto; Melhora.

Os critérios de inclusão foram: artigos indexados nas bases de dados PubMed, LILACS, Web of Knowledge e CINAHL, artigos com foco em populações carentes, em comunidades onde havia ESFs instaladas, artigos publicados na íntegra em inglês e em português e publicados nos últimos 10 anos. Os critérios de exclusão foram artigos realizados fora do Brasil, revisões de literatura, teses e dissertações. Na base de dados PubMed, foram encontrados 403 artigos, na LILACS 72, Web of Knowledge 70, e na e CINAHL 14, totalizando 559 artigos.

Para a seleção dos artigos, foi realizada a leitura do título, resumo e palavras-chave dos estudos. Em caso de dúvida a respeito da seleção, optou-se por incluir o estudo para decisão final após leitura de seu conteúdo na íntegra. Assim, foram pré-selecionados 45 artigos que 
se enquadravam nos objetivos deste estudo. Após leitura de todos os artigos na íntegra, 12 destes foram selecionados para o estudo e 33 excluídos, pois não se enquadravam nos critérios de inclusão e exclusão. Para a organização e tabulação dos dados, foi utilizado um instrumento de coleta de dados contendo o título da pesquisa, ano, autores, periódico de publicação, delineamento do estudo, local onde foi desenvolvida a pesquisa, objetivos do artigo, participantes, resultados encontrados e conclusão/considerações. Posteriormente, foram extraídas as principais informações abordadas em cada artigo e que se correlacionavam com o objetivo do estudo. Em seguida, foi realizada, exaustivamente, a leitura da síntese dos artigos, com o propósito de verificar a contribuição de cada estudo para a elucidação da questão norteadora, de forma a atingir objetivo previsto.

\section{Resultados}

Os estudos analisados foram publicados no período de 2005 a 2011, sendo que três estavam em inglês e nove em português, todos desenvolvidos no Brasil. Dentre eles, quatro utilizavam uma abordagem quantitativa e oito qualitativa. O quadro 1 sintetiza os estudos analisados neste trabalho. 
Quadro 1. Distribuição dos artigos analisados segundo título, autores, local do estudo, ano de publicação, delineamento do estudo, objetivos, resultados principais e conclusão.

\begin{tabular}{|c|c|c|c|c|c|}
\hline Título/Primeiro autor & $\begin{array}{l}\text { País do estudo e } \\
\text { ano da } \\
\text { publicacãa }\end{array}$ & $\begin{array}{c}\text { Delineamento do } \\
\text { estudo }\end{array}$ & Objetivos & Resultados principais & Conclusão \\
\hline $\begin{array}{l}\text { Realidade sociopolítica, } \\
\text { ambiental e de saúde de } \\
\text { famílias pertencentes a uma } \\
\text { comunidade vulnerável. } \\
\text { Marzari } \mathrm{CK}^{(12)}\end{array}$ & $\begin{array}{l}\text { Rio Grande do } \\
\text { Sul/ } 2009\end{array}$ & $\begin{array}{l}\text { Exploratório, de } \\
\text { caráter qualitativo }\end{array}$ & $\begin{array}{l}\text { Conhecer a percepção } \\
\text { de lideranças, } \\
\text { profissionais da saúde e } \\
\text { usuários acerca da } \\
\text { cidadania e melhoria da } \\
\text { saúde. }\end{array}$ & $\begin{array}{l}\text { O estudo demonstra uma } \\
\text { realidade de pobreza e exclusão } \\
\text { social, mesmo contando com as } \\
\text { políticas de atenção do SUS, } \\
\text { com equipe de ESF. }\end{array}$ & $\begin{array}{l}\text { As comunidades vulneráveis ainda } \\
\text { convivem com a baixa cobertura } \\
\text { assistencial, acesso precário, } \\
\text { descontinuidade, falta de resolutividade } \\
\text { nos serviços de saúde e frágil } \\
\text { integração intersetorial. }\end{array}$ \\
\hline $\begin{array}{l}\text { Access to, use of and } \\
\text { satisfaction with health } \\
\text { services among adults } \\
\text { enrolled in Brazil's Family } \\
\text { health. Macinko J. (13) }\end{array}$ & Brasil/2008 & $\begin{array}{l}\text { Descritivo, } \\
\text { quantitativo, não } \\
\text { experimental, } \\
\text { transversal }\end{array}$ & $\begin{array}{l}\text { Avaliar os efeitos da ESF } \\
\text { no acesso, uso e } \\
\text { satisfação com o serviço } \\
\text { de saúde. }\end{array}$ & $\begin{array}{l}\text { O estudo mostra que pessoas } \\
\text { que habitam áreas cobertas } \\
\text { pelas ESF eram mais propensas } \\
\text { a terem acesso a medicações, } \\
\text { atendimento médico e } \\
\text { odontológico. }\end{array}$ & $\begin{array}{l}\text { O PSF apresenta-se importante para } \\
\text { populações de menor e maior nível } \\
\text { socioeconômico, mostra-se equitativo e } \\
\text { tem tendência de tornar o acesso cada } \\
\text { vez mais universal. }\end{array}$ \\
\hline $\begin{array}{l}\text { An analysis of actions to } \\
\text { promote health in } \\
\text { underprivileged urban areas: a } \\
\text { case in Brazil. Moreira ECR. } \\
\text { (14) }\end{array}$ & $\begin{array}{l}\text { Rio de } \\
\text { Janeiro/2011 }\end{array}$ & $\begin{array}{l}\text { Estudo } \\
\text { exploratório de } \\
\text { abordagem } \\
\text { qualitativa }\end{array}$ & $\begin{array}{l}\text { Analisar as ações da } \\
\text { ESF. }\end{array}$ & $\begin{array}{l}\text { Os resultados mostram que } \\
\text { fatores políticos, estruturais, } \\
\text { financiamento e desarticulação } \\
\text { dos serviços dificultam a } \\
\text { eficácia da ESF. }\end{array}$ & $\begin{array}{l}\text { Observa-se que em meio às } \\
\text { dificuldades, as ações têm perdido sua } \\
\text { efetividade e em alguns casos têm tido } \\
\text { sua implementação impedida. }\end{array}$ \\
\hline $\begin{array}{l}\text { Autoavaliação da estratégia } \\
\text { saúde da família por } \\
\text { enfermeiros. Oliveira WMA. } \\
\text { (15) }\end{array}$ & Goiás/2010 & $\begin{array}{l}\text { Descritivo } \\
\text { exploratório de } \\
\text { abordagem } \\
\text { quantitativa }\end{array}$ & $\begin{array}{l}\text { Analisar o contexto da } \\
\text { estratégia saúde da } \\
\text { família (ESF) em um } \\
\text { município de Goiás. }\end{array}$ & $\begin{array}{l}\text { Os resultados apontaram } \\
\text { melhorias ou mudanças locais } \\
\text { após a implantação da ESF e } \\
\text { aumento no acesso. }\end{array}$ & $\begin{array}{l}\text { Pode-se afirmar que a ESF está } \\
\text { alcançando os objetivos propostos, } \\
\text { pois tem provocado mudanças } \\
\text { positivas na vida da população e } \\
\text { ampliado o acesso à saúde. }\end{array}$ \\
\hline $\begin{array}{l}\text { Avaliação da resolutividade do } \\
\text { Programa Saúde da Família } \\
\text { em municípios de pequeno } \\
\text { porte no Estado de Minas } \\
\text { Gerais. Veloso RCA. (16) }\end{array}$ & $\begin{array}{l}\text { Minas } \\
\text { Gerais/2009 }\end{array}$ & $\begin{array}{l}\text { Estudo ecológico } \\
\text { do tipo } \\
\text { comparação de } \\
\text { séries históricas }\end{array}$ & $\begin{array}{l}\text { Avaliar a atuação do PSF } \\
\text { em relação a Internações } \\
\text { Hospitalares. }\end{array}$ & $\begin{array}{l}\text { O estudo mostra o aumento da } \\
\text { cobertura populacional pelo PSF } \\
\text { e a redução nas Internações } \\
\text { Hospitalares. }\end{array}$ & $\begin{array}{l}\text { É possível dizer que os recursos do } \\
\text { Governo Estadual e Federal estão } \\
\text { sendo bem empregados e utilizados } \\
\text { para a melhoria da qualidade da } \\
\text { Atenção Primária à Saúde. }\end{array}$ \\
\hline
\end{tabular}




\begin{tabular}{|c|c|c|c|c|c|}
\hline $\begin{array}{l}\text { Desempenho do PSF no Sul e } \\
\text { no Nordeste do Brasil: } \\
\text { avaliação institucional e } \\
\text { epidemiológica } \\
\text { da Atenção Básica à Saúde. } \\
\text { Facchini LA. (17) }\end{array}$ & $\begin{array}{l}\text { Alagoas, Paraíba, } \\
\text { Pernambuco, } \\
\text { Piauí, Rio Grande } \\
\text { do Norte, Rio } \\
\text { Grande do Sul e } \\
\text { Santa } \\
\text { Catarina/2006 } \\
\end{array}$ & $\begin{array}{l}\text { Descritivo, } \\
\text { quantitativo, não } \\
\text { experimental, } \\
\text { transversal }\end{array}$ & $\begin{array}{l}\text { Avaliar o desempenho do } \\
\text { PSF no Sul e no } \\
\text { Nordeste } \\
\text { do Brasil. }\end{array}$ & $\begin{array}{l}\text { Os resultados demonstram a } \\
\text { necessidade de expansão da } \\
\text { ESF na região Sul e a } \\
\text { consolidação na região } \\
\text { Nordeste, principalmente devido } \\
\text { a aspectos políticos. }\end{array}$ & $\begin{array}{l}\text { O PSF representou um esforço bem- } \\
\text { sucedido de promoção da equidade, } \\
\text { principalmente nas regiões com } \\
\text { populações mais vulneráveis. }\end{array}$ \\
\hline $\begin{array}{l}\text { Estratégia de Saúde da } \\
\text { Família em Florianópolis: } \\
\text { integração, coordenação e } \\
\text { posição na rede assistencial. } \\
\text { Sisson MC. }{ }^{(18)}\end{array}$ & $\begin{array}{l}\text { Santa } \\
\text { Catarina/2011 }\end{array}$ & $\begin{array}{l}\text { Qualitativo } \\
\text { (estudo de caso) }\end{array}$ & $\begin{array}{l}\text { Examinar o modelo } \\
\text { assistencial da atenção } \\
\text { básica em saúde em } \\
\text { Florianópolis, a partir da } \\
\text { implementação da ESF. }\end{array}$ & $\begin{array}{l}\text { O estudo mostra que o PSF } \\
\text { causa um impacto positivo na } \\
\text { população, principalmente na de } \\
\text { baixa renda. }\end{array}$ & $\begin{array}{l}\text { Avanços significativo no município, } \\
\text { devido a construção de estratégias } \\
\text { para superar a fragmentação dos } \\
\text { cuidados, com investimentos em } \\
\text { tecnologias de informação e } \\
\text { comunicação e a criação de serviços } \\
\text { especializados municipais e um } \\
\text { sistema de regulação. }\end{array}$ \\
\hline $\begin{array}{l}\text { Going to scale with } \\
\text { community-based primary } \\
\text { care: } \\
\text { An analysis of the family } \\
\text { health program and infant } \\
\text { mortality } \\
\text { in Brazil, 1999-2004. Macinko } \\
\text { J. (19) }\end{array}$ & Brasil/2007 & $\begin{array}{l}\text { Ecológico, } \\
\text { transversal }\end{array}$ & $\begin{array}{l}\text { Avaliar os efeitos do } \\
\text { PSF nas variações } \\
\text { microrregionais de } \\
\text { mortalidade infantil, } \\
\text { mortalidade neonatal e } \\
\text { pós-neonatal. }\end{array}$ & $\begin{array}{l}\text { Os resultados mostram que a } \\
\text { Taxa de Mortalidade Infantil } \\
\text { declinou cerca de } 13 \% \text { de } 1999 \\
\text { a } 2004 \text {, enquanto a cobertura do } \\
\text { programa de saúde da família } \\
\text { aumentou cerca de } 14 \% \text { a } 60 \% \text {. }\end{array}$ & $\begin{array}{l}\text { A expansão da cobertura do ESF, } \\
\text { entrelaçados com outros } \\
\text { desenvolvimentos socioeconômicos, } \\
\text { foram consistentes com as reduções da } \\
\text { mortalidade infantil no nível primário de } \\
\text { casos sensíveis à atenção. }\end{array}$ \\
\hline $\begin{array}{l}\text { Impacto das ações de } \\
\text { imunização pelo Programa } \\
\text { Saúde da Família na } \\
\text { mortalidade infantil por } \\
\text { doenças evitáveis em Olinda, } \\
\text { Pernambuco } \\
\text { Brasil. Guimarães TMR. }{ }^{(20)}\end{array}$ & Pernambuco/2009 & $\begin{array}{l}\text { Ecológico, } \\
\text { longitudinal }\end{array}$ & $\begin{array}{l}\text { Avaliar o impacto das } \\
\text { ações de imunização } \\
\text { pelo PSF na mortalidade } \\
\text { infantil por doenças } \\
\text { evitáveis em Olinda, no } \\
\text { período de sua } \\
\text { implantação (1995) até o } \\
\text { ano de 2002. } \\
\end{array}$ & $\begin{array}{l}\text { Devido às ações de imunização } \\
\text { realizadas pelo PSF, verificou- } \\
\text { se aumento das médias de } \\
\text { coberturas vacinais, e houve } \\
\text { redução dos casos de } \\
\text { mortalidade por } \\
\text { imunoprevenção. }\end{array}$ & $\begin{array}{l}\text { Acredita-se que a melhoria nas } \\
\text { coberturas vacinais e a redução da } \\
\text { mortalidade infantil por causas } \\
\text { evitáveis, no município estudado, } \\
\text { possam estar relacionadas ao trabalho } \\
\text { desenvolvido pelo PSF. }\end{array}$ \\
\hline $\begin{array}{l}\text { Intersetorialidade e vínculo no } \\
\text { controle da tuberculose na } \\
\text { Saúde da Família. Sá LD. }{ }^{(21)}\end{array}$ & Paraíba/2011 & $\begin{array}{l}\text { Qualitativo (grupo } \\
\text { focal) }\end{array}$ & $\begin{array}{l}\text { Analisar o desempenho } \\
\text { das equipes de Saúde da } \\
\text { Família no controle da } \\
\text { tuberculose. }\end{array}$ & $\begin{array}{l}\text { ESF proporcionou avanços em } \\
\text { relação ao controle da TB } \\
\text { dentre eles desenvolvendo } \\
\text { ações de prevenção, cura e } \\
\text { reabilitação. }\end{array}$ & $\begin{array}{l}\text { Considera-se que apesar das } \\
\text { limitações existem o esforço e o } \\
\text { compromisso das ESFs em garantir o } \\
\text { êxito do tratamento das pessoas } \\
\text { acometidas pela TB. }\end{array}$ \\
\hline
\end{tabular}




\begin{tabular}{|c|c|c|c|}
\hline $\begin{array}{l}\text { Resultados alcançados com a } \\
\text { estratégia saúde da } \\
\text { Família após cinco anos de } \\
\text { implantação em uma cidade } \\
\text { do interior de minas gerais. } \\
\text { Guedes HM. }{ }^{(22)}\end{array}$ & $\begin{array}{c}\text { Minas } \\
\text { Gerais/2007 }\end{array}$ & $\begin{array}{l}\text { Exploratório, } \\
\text { quantitativo }\end{array}$ & $\begin{array}{l}\text { Comparar os resultados } \\
\text { de ações de atenção } \\
\text { básica relativos a dois } \\
\text { momentos: antes e } \\
\text { depois da implantação do } \\
\text { ESF }\end{array}$ \\
\hline $\begin{array}{l}\text { Significado da atuação da } \\
\text { equipe da Estratégia de } \\
\text { Saúde da Família em uma } \\
\text { comunidade socialmente } \\
\text { vulnerável. Backes DS. }{ }^{(23)}\end{array}$ & Brasil/2011 & $\begin{array}{l}\text { Qualitativo (teoria } \\
\text { fundamentada } \\
\text { nos dados) }\end{array}$ & $\begin{array}{l}\text { Compreender o } \\
\text { significado da atuação } \\
\text { profissional de uma ESF } \\
\text { em uma comunidade } \\
\text { vulnerável. }\end{array}$ \\
\hline
\end{tabular}

Houve diminuição considerável

do número de internações

hospitalares, aumento do

número de ações de saúde da

mulher e da criança, adesão aos

programas de hipertensão,

diabetes, hanseníase,

tuberculose e DST/AIDS.

A ESF pode ser considerada

uma estratégia facilitadora $e$

estimuladora das redes de

cuidado de modo especial nas

comunidades socialmente

vulneráveis.
A pesquisa mostrou resultados

satisfatórios no que tange a indicadores

de saúde de uma comunidade em

relação à implantação da ESF.

Resultados concretos, demonstrados estatisticamente, revelam que a saúde da comunidade melhorou.

Constata-se que o significado da ESF em uma comunidade socialmente vulnerável possibilita relacionamento e diálogo, proporcionando o fortalecer da autonomia dos diferentes atores envolvidos no cuidado em saúde. 


\section{Discussão}

A análise dos artigos sugere que onde houve implantação da ESF e ao longo de sua estruturação, houve considerável melhoria na qualidade e condições de vida dos indivíduos assistidos, de suas famílias e comunidades. Os dados indicam a efetividade das ações de promoção à saúde implementadas por toda a equipe, em seus vários ramos de atuação (13), (17), (26). (Quadro 1). De acordo com a análise dos resultados, todos os PSFs estavam localizados em regiões em que a população vivia em condições de média a extrema pobreza (13), (26). (Quadro 1).

Nota-se que, desde o início da implantação dos PSFs, pode-se contatar um aumento de sua cobertura em diversas regiões do país. (20) (22), (23). (Quadro 1). Foi também ressaltada a efetividade das ações de promoção à saúde (13), (17), (22), (Quadro 1) causando mudanças na realidade da saúde das localidades estudadas. Houve crescente aumento do acesso anual da população à consulta médica, odontológica e a medicamentos, (13) (17) (22) (Quadro 1) gerando assim equidade e universalidade de acesso à saúde (13) (19) (22) (24) (Quadro 1) e a possibilidade de ampliar a qualidade de vida das pessoas, de acordo com os princípios doutrinários do SUS (13) (Quadro 1).

Os artigos evidenciaram que os ESFs não somente beneficiam a população de baixa renda, mas também as de renda maior que utilizam os serviços, (13) (20) (21) (Quadro 1) e sustentam a satisfação da população com os atendimentos e serviços prestados (13) (Quadro 1). Observa-se, também, uma estruturação da articulação da Estratégia de Saúde da Família em conjunto com os vários equipamentos de serviço de saúde, propondo-se um cuidado integral aos usuários. Um dos fatores da integração desses ajustes é o incentivo financeiro dado pelos governos para a sustentabilidade das ações. Outrossim, ainda existem disparidades na distribuição dos recursos de financiamento. Contudo, a despeito das discrepâncias em algumas regiões do país, estas ações vêm obtendo êxito. (17) (18) (21) (Quadro 1). Um dos artigos mostra que o financiamento, quando concedido, contribui com a melhora da unidade e o avanço das ações de promoção (18) (Quadro 1).

Os estudos salientam um significativo esforço por parte dos profissionais na elaboração e implementação de ações de promoção à saúde, mesmo que em unidades em que os profissionais não têm especializações em Saúde da Família (16) (19) (20) (22) (23) (Quadro 1). Entretanto, um dos artigos aponta a preocupação do enfermeiro em se qualificar, sendo 
este uma peça chave na integração e articulação dos profissionais da unidade. Além disso, o enfermeiro possui grande importância como líder de equipe na elaboração, implementação e avaliação das ações de promoção (17) (Quadro 1).

Da análise dos artigos selecionados, pode-se evidenciar que com o aumento das visitas domiciliares, cria-se um vínculo que possibilita a melhor investigação dos indicadores de saúde e pode-se, assim, elaborar um plano de cuidados amplo e integral para cada família dentro de seus respectivos contextos (22) (25) (Quadro 1). Pode-se, também, traçar estratégias individualizadas para cada membro considerando o papel que desempenham no contexto de sua família. Além disso, com as visitas domiciliares e por meio de ações baseadas na educação da população, os usuários são incentivados a assumirem sua corresponsabilidade no processo de saúde-doença (13) (17) (19) (20) (25) (26) (Quadro 1).

A realidade das famílias visitadas, caracterizadas pela falta de estrutura familiar, vícios, pobreza, doenças sexualmente transmissíveis, dentre outros fatores, gera nos profissionais a necessidade de se aperfeiçoarem. Os desafios encontrados os instigam a cada vez mais aperfeiçoarem seus conhecimentos para que quando voltem tragam algo que por mais ínfimo que pareça possa ser o início da transformação daquela realidade familiar (24).

Dentre as mudanças causadas pelas ações de promoção, destaca-se o aumento da imunização e queda na taxa de mortalidade infantil, (21) (23) (Quadro 1) sendo está um resultado importante para o país, por ser um indicador usado para classificação do Índice Desenvolvimento Humano (IDH) (28) (Quadro 1). A análise dos resultados também sugere que após a implementação da ESF houve aumento nos exames preventivos de cânceres como o papanicolau e outros, o que facilita o diagnóstico precoce e aumento da sobrevida no caso de câncer. Houve também aumento de consultas de pré-natal e do controle de doenças crônicas como Hipertensão e Diabetes, através do programa Hiperdia (17) (18) (23) (25) (Quadro 1). Ações de controle e busca ativa da Tuberculose também foram efetivas, apesar dos profissionais enfrentarem problemas como falta de conhecimento sobre doença, dificuldade do enfrentamento do estigma e a falta de integração e articulação dos serviços para a não fragmentação e continuidade do tratamento (17) (18) (23) (25) (Quadro 1).

Apesar da melhora evidenciada, a ESF encontra vários obstáculos em seu caminho, desde sua implantação e estruturação. Há grande resistência por parte de alguns profissionais, em relação a mudanças do modelo curativo para o modelo preventivo e de 
promoção de saúde proposta pela estratégia. (16) (19) (24) (Quadro 1). Observa-se que em grande parte do país há um déficit de incentivos financeiros e por parte dos governos, o que contribui para a precariedade das unidades. Esta carência acarreta falta de recursos humanos que, consequentemente, faz com que as equipes estejam incompletas, não sendo este um problema isolado (16) (Quadro 1). Outro fator que prejudica a eficácia da atuação da ESF é a má infraestrutura e a influência dos interesses políticos locais ou regionais, presentes ainda em várias regiões do país, o que impede ações de serem realizadas e faz com que haja uma queda da eficiência das que são realizadas (16) (19) (20) (22) (Quadro 1). Outro problema enfrentado é a baixa qualificação dos profissionais em relação à Estratégia de Saúde da Família (16) (19) (20) (22) (23) (Quadro 1). Muitas vezes, os profissionais foram simplesmente realocados de acordo com a necessidade do serviço, sem o devido treinamento ou qualificação. Além disso, os artigos mencionam a falta de médicos nas unidades ou falta de comprometimento com o cumprimento de suas cargas horárias e a baixa adesão ao modelo de promoção de saúde, o que faz com que suas ações tendam ao modelo curativo (16) (20) (24) (Quadro 1).

A análise também mostra que os PSFs enfrentam problemas com a demanda excessiva de população o que geralmente ocasiona sobrecarga dos profissionais (16) (22) (25) (Quadro 1). Nota-se que em vários lugares onde existe uma rede de saúde desarticulada, os serviços como regulação, referência e contra referência, laboratórios e outros, não são expressivos ou são inexistentes, causando uma fragilização na implementação das ações com comprovada eficácia e as dificultando nos locais onde a estrutura das ESFs é precária (16) (17) (19) (20) (22) (24) (Quadro 1).

Em alguns tipos de intervenções e ações mediatas, a assistência prestada no setor privado, no âmbito da prevenção primária, tem tido melhor êxito no país devido a incentivos financeiros, melhor estrutura física das instalações e por muitas vezes menor clientela, o que facilita o cuidado. Este cenário causa impressão de uma melhor assistência, aos olhos da população. Entretanto, em um dos artigos, a assistência no PSF foi comparada com a assistência prestada no setor privado e os resultados mostraram que, mesmo em meio à pobreza, a população recebeu um cuidado em saúde igual ou superior ao privado (16) (Quadro 1). 


\section{Conclusão}

Este estudo buscou avaliar evidências disponíveis na produção científica sobre a atuação da Estratégia Saúde da Família na garantia do direito de saúde de populações mais vulneráveis, verificando que a mudança de vida gerada na população proporciona o maior acesso ao serviço de saúde especialmente por populações mais desfavorecidas, contribuindo, para a superação das disparidades na qualidade de saúde e/ou até mesmo sociais.

No Brasil, um país de proporções continentais, a estratégia está implantada desde 1994, e assim como a própria consolidação do SUS, é uma estratégia nova e ainda passa por grandes dificuldades, apesar de sua potencialidade como agente de transformação de realidade e sustentação dos direitos dos indivíduos, dentre eles o direito à saúde.

Nota-se que com esta estratégia há a criação de um vínculo mais profundo, trazendo o profissional de saúde para dentro da casa do usuário e possibilitando uma oportunidade ímpar de conhecer a real situação das famílias, traçar planos de cuidados e estratégias específicas, gerando uma forte base de confiança no profissional e possibilitando 0 fortalecimento dos conhecimentos transmitidos, da corresponsabilidade e da autonomia do usuário.

Observa-se que a estratégia é inovadora causando impactos significativos na sociedade, comunidade, família e no âmbito individual, apesar de dificuldades com a mudança do modelo de assistência, falta de vontade política e de recursos financeiros e humanos. Portanto, apesar das dificuldades enfrentadas, esta estratégia pode possibilitar uma melhora na saúde populacional, não somente física, mas, também, mental, política e social. Constata-se que o direito à saúde vem sendo afirmado por atitudes fundamentadas na justiça e igualdade, respaldadas pela Constituição e por movimentos de luta pela equidade.

\section{Referências}

1. Lourenço LFL, Danczuk RFT, Painazzer D, Paula Junior NF, ARCR Maia, EKA Santos. A Historicidade filosófica do Conceito Saúde. Centro de memoria da enfermagem brasileira associação brasileira de enfermagem 2012 Here- revista eletrônica (3)1 -17-35 Disponível 
em: http://www.abennacional.org.br/centrodememoria/here/vol3num1artigo2.pdf. [Acesso em 10 out 2013]

2. Ventura, CAA. Saúde mental e direitos humanos: o processo de construção da cidadania das pessoas portadoras de transtornos mentais. Ribeirão Preto, 2011.199p. Tese de Livre Docência, apresentada à Escola de Enfermagem de Ribeirão Preto/USP. Área de concentração: Enfermagem Psiquiátrica

3. Declaração universal dos direitos humanos. 1948. Adotada e proclamada pela resolução 217 a (III) da assembleia geral das nações unidas em 10 de dezembro de 1948, Disponível em: http://portal.mj.gov.br/sedh/ct/legis_intern/ddh_bib_inter_universal.htm [Acesso e, 10 out 2013

4. Pacto da ONU sobre Direitos Econômicos, Sociais e Culturais. 1966 Adotado pela Resolução 2200(A) da Assembleia Geral da ONU Nova lorque de 16 de dezembro de 1966. Disponível em: http://www.gddc.pt/direitos-humanos/textos-internacionaisdh/tidhuniversais/cidh-dudh-direitos-civis.html [Acesso em 10 out 2013.

5. Declaração de Alma-Ata 1978. Conferência internacional sobre cuidados primários de saúde. Alma-Ata, URSS, 6-12 de setembro de 1978 Disponível em: http://www.saudepublica.web.pt/05-promocaosaude/Dec_Alma-Ata.htm [Acesso em 10 out 2013

6. Carta de ottawa 1986. Primeira conferência internacional sobre promoção da saúde. Ottawa, novembro de 1986. Disponível em:

http://www.mpba.mp.br/atuacao/cidadania/gesau/legislacao/internacionais/carta_ottawa.pdf [Acesso em 10 out 2013]

7 Polignano MV.. História das políticas de saúde no Brasil: uma pequena revisão.

Disponível em: http://www.saude.mt.gov.br/ces/arquivo/2165/ivros [ Acesso em 10 out 2013

8. Brasil. Constituição (1988). Constituição da República Federativa do Brasil. Brasília, DF: Senado,1988. Disponível em:

http://www.senado.gov.br/legislacao/const/con1988/CON1988_05.10.1988/CON1988.pdf [Acesso em 10 out 2013].

9. Siqueira, NL. Desigualdade Social em Saúde no Brasil. Universidade Federal de Juiz de Fora.2011. Revista Virtual revista eletrônica (9). Disponível em:

http://www.ufjf.br/virtu/files/2011/09/DESIGUALDADE-SOCIAL-EM-SA\%C3\%9ADE-NO-

BRASIL.pdf. [ Acesso em 10 nov 2013]

10. Guimarães M.S.; Novaes S.C. Páginas de Bioética. Porto Alegre. Instituto de Medicina Tropical. Atualizado em 03 de agosto de 2017. Disponível em:

https://www.ufrgs.br/bioetica/vulnera.htm [ Acesso em 14 ago 2017].

11. Brasil. Ministério da Saúde. Disponivel em

http://dab.saude.gov.br/portaldab/ape_esf.php. [ Acesso em 20 out 2013]. 
12. Mendes KS, Silveira RCCP, Galvão CM. Revisão integrativa: método de pesquisa para a Incorporação de evidências na saúde e na enfermagem. Texto Contexto Enferm 2008; 17(4):758-64. Disponível em: http://www.scielo.br/pdf/spp/v17n2/a12v17n2.pdf. [ Acesso em 12 maio 2013].

13. Marzari, CK et al. Realidade sociopolítica, ambiental e de saúde de famílias pertencentes a uma comunidade vulnerável. Ciênc. saúde coletiva 2013; 18(1): 77-84. Disponível em :http://www.scielo.br/pdf/csc/v18n1/09.pdf..[Acesso em 17.out.2013]

14. Saúde da Família: uma estratégia para a reorientação do modelo assistencial. Brasília. Ministério da Saúde, 1997. Disponível em: http://bvsms.saude.gov.br/bvs/publicacoes/cd09_16.pdf. [ Acesso em 14 ago 2017].

15. Portão Brasil. Brasília. Saúde. Atualizado em 29 de julho de 2014. Disponível em: http://www.brasil.gov.br/saude/2012/07/cresce-o-numero-de-equipes-que-atuam-naatencao-basica-de-saude por Portal Brasil. [ Acesso em14 ago 2017].

16. Macinko J, Lima Costa MF. Access to, use of and satisfaction with health services among adults enrolled in Brazil's Family Health Strategy: evidence from the 2008 National Household Survey. Tropical Medicine \& International Health 2012; 17: 36-42. Disponivel em http://onlinelibrary.wiley.com/doi/10.1111/j.1365-3156.2011.02866.x/pdf. [Acesso em 15 out 2013].

17. Moreira ECR, O'Dwyer G. An analysis of actions to promote health in underprivileged urban areas: a case in Brazil. BMC Family Practice 2011; 14(1): 80-90. Disponível em: http://www.biomedcentral.com/1471-2296/14/80/. [Acesso em 15 out 2013]

18. Oliveira WMA, Bezerra ALQ. Auto avaliação da estratégia saúde da família por enfermeiros. Rev. enferm. UERJ; 2011; 19(1): 20-25. Disponível em: http://www.facenf.uerj.br/v19n1/v19n1a04.pdf. [Acesso em 17 out.2013]

19. Veloso RC, Araújo MRN. Avaliação da resolutividade do programa saúde da família em municípios de pequeno porte no Estado de Minas Gerais. Rev APS 2009; 12:238-43. Disponivel em: http://www.aps.ufjf.br/index.php/aps/article/view/313/222.[ Acesso em 17 out 2013].

20. Facchini LA, et al. Desempenho do PSF no Sul e no Nordeste do Brasil: avaliação institucional e epidemiológica da Atenção Básica à Saúde. Ciênc. saúde coletiva 2006; 11(3): 669-81. Disponível em: http://www.scielo.br/pdf/csc/v11n3/30982.pdf. [ Acesso em 17 out 2013].

21. Sisson MC, et al. Estratégia de Saúde da Família em Florianópolis: integração, coordenação e posição na rede assistencial. Saude soc. 2011; 20(4): 991-1004. Disponível em http://www6.ensp.fiocruz.br/repositorio/sites/default/files/arquivos/EstrategiaFlorianopolis.pd f. [ Acesso em 17 out 2013]. 
22. Macinko J, Souza MFM, Guanais FC, Simooes CCS. Going to scale with communitybased primary care: An analysis of the family health program and infant mortality in Brazil, 1999-2004. Social Science \& Medicine 2007; 65(10): 71-8. Disponível em:

http://www.sciencedirect.com/science/article/pii/S0277953607003553\#. [ Acesso em 15 out 2013.

23. Guimarães TMR, Alves JGB, Tavares MMF. Impacto das ações de imunização pelo Programa Saúde da Família na mortalidade infantil por doenças evitáveis em Olinda, Pernambuco, Brasil. Cad. Saúde Pública 2009; 29(4): 868-76. Disponível em: http://www.scielo.br/pdf/csp/v25n4/18.pdf. [Acesso em 17 out 2013].

24. Sá LD, et al. Intersectorality and bonding in tuberculosis control in Family Health. Rev. Latino-Am. Enfermagem 2011;19(2): 387-95. Disponível em:

http://www.scielo.br/pdf/rlae/v19n2/22.pdf. [Acesso em 15 out 2013]

25. Guedes HM, Paula LD, Nakatani AYK, Coelho AB. Resultados alcançados com a estratégia saúde da família após cinco anos de implantação em uma cidade do interior de Minas Gerais. Rev. Min. Enferm. 2007; 11(4): 363-68. Disponivel em out 2013

26. Backes DS, et al. Significado da atuação da equipe da Estratégia de Saúde da Família em uma comunidade socialmente vulnerável. Ciênc. Saúde coletiva 2012; 17(5):1151-7. Disponível em: http://www.scielo.br/pdf/csc/v17n5/a09v17n5.pdf. [ Acesso em 17 out 2013.

27. Mendes EV. As redes de atenção à saúde. Ciênc. Saúde coletiva 2010; 15(5): 2297305. Disponível em:

http://www.abrasco.org.br/UserFiles/File/ABRASCODIVULGA/2011/RASMendes.pdf. [ Acesso em 20 outo.2013]

28. Relatório do Desenvolvimento Humano 2013. A Ascensão do Sul: Progresso Humano num Mundo Diversificado. Disponivel

em:http://www.un.cv/files/HDR2013\%20Report\%20Portuguese.pdf.[ Acesso em 20 out 2013].

Recebido em: 4.9.2017

Aprovado em:23.9.2017

\section{Como citar este artigo:}

Eugenio SJ, Ventura CAA. Estratégia saúde da família: iniciativa pública destinada a populações vulneráveis para garantia do direto à saúde - uma revisão crítica da literatura. Revista Cadernos Ibero-Americanos de Direito Sanitário. 2017 jul./set, 6(3):129-143. 